\title{
CRYSTAL STRUCTURE, AND FLUORESCENT PROPERTIES OF A 1D Zn(II) COORDINATION POLYMER BASED ON 5-NITRO-1,3-BENZENEDICARBOXYLIC ACID
}

\author{
X.-J. Xu \\ School of Chemistry \& Chemical Engineering, Yancheng Teachers University, Yancheng, Jiangsu 224002, P.R. \\ China \\ E-mail: xxjyctu@gmail.com
}

Received October, 25, 2014

Revised-June, 12, 2015

A one-dimensional $\mathrm{Zn}(\mathrm{II})$ complex $\left[\mathrm{Zn}(\mathrm{Im})_{2}\left(\mathrm{NO}_{2}-\mathrm{BDC}\right)\right]_{n}(\mathbf{1})\left(\mathrm{Im}=\right.$ Imdazole, $\mathrm{NO}_{2}-\mathrm{H}_{2} \mathrm{BDC}=$ $=5$-nitro-1,3-benzenedicarboxylic acid) is synthesized and characterized using single crystal $\mathrm{X}$-ray diffraction, IR spectroscopy and elemental analysis. Single crystal X-ray diffraction analysis reveals that complex $\mathbf{1}$ is a one-dimensional chain polymer with a $\mathrm{Zn} \cdots \mathrm{Zn}$ separation of 9.6190(2) $\AA$ arranged parallel to the $\left(\begin{array}{lll}1 & 0 & 0\end{array}\right)$ crystal direction. In addition, the luminescence measurements reveal that complex 1 exhibits strong fluorescent emissions in the solid state at room temperature.

DOI: $10.15372 / J S C 20150529$

Ke y w o r d s: Zn(II) complex, 5-nitro-1,3-benzenedicarboxylic acid, crystal structure, onedimensional chain, fluorescent property.

The design and characterization of coordination polymers remains a popular basic research not only because of the intriguing variety of topologies but also the potential utility in nonlinear optics, magnetism, gas storage, ion exchange, luminescence, second harmonic generation and catalysis, etc. [ $1-3]$. It is well known that the choice of the organic ligand is the key factor that influences the construction of coordination polymers with interesting structures [4-5]. The most effective and facile approach to coordination polymers is to utilize aromatic dianionic dicarboxylate ligands to link metal ions while providing the structural integrity [ $6-8]$. Because of the versatile bridging modes for two carboxyl groups and one nitro group, the 5-nitro-1,3-benzenedicarboxylic acid ligand has been widely used to build coordination polymers [9-10]. On the other hand, imdazole is a good building block for the construction of coordination polymers and multidimensional supramolecular networks [11, 12 ]. Here, we use 5-nitro-1,3-benzenedicarboxylic acid $\left(\mathrm{NO}_{2}-\mathrm{H}_{2} \mathrm{BDC}\right)$ and imdazole (Im), generating a new one dimensional $\mathrm{Zn}(\mathrm{II})$ coordination complex $\left[\mathrm{Zn}(\mathrm{Im})_{2}\left(\mathrm{NO}_{2}-\mathrm{BDC}\right)\right]_{n}(\mathbf{1})$, the crystal structure of which we now report. In addition, the fluorescent properties of complex 1 have been investigated.

Experimental. All reagents and solvents were purchased and used without further purification. The IR spectra were obtained within $4000-400 \mathrm{~cm}^{-1}$ as $\mathrm{KBr}$ disks on a VECTOR 22 spectrometer. Elemental analysis was performed on a Perkin Elmer 240C elemental analyzer. Powder X-ray diffraction (PXRD) patterns were obtained on a Shimadzu XRD-6000 X-ray diffractometer with $\mathrm{Cu} K_{\alpha}$ $(\lambda=1.5418 \AA)$ radiation at room temperature. Solid-state fluorescence spectra were recorded on a Fluoro Max-P spectrophotometer at room temperature.

Synthesis of $\left[\mathrm{Zn}(\mathrm{Im})_{2}\left(\mathrm{NO}_{2}-\mathrm{BDC}\right)\right]_{n}$. A mixture of $\mathrm{NO}_{2}-\mathrm{H}_{2} \mathrm{BDC}(21.1 \mathrm{mg}, 0.1 \mathrm{mmol}), \mathrm{Im}$ (13.8 mg, $0.2 \mathrm{mmol}), \mathrm{Zn}\left(\mathrm{NO}_{3}\right)_{2} \cdot 6 \mathrm{H}_{2} \mathrm{O}(29.7 \mathrm{mg}, 0.1 \mathrm{mmol}), \mathrm{LiOH} \cdot \mathrm{H}_{2} \mathrm{O}(4.2 \mathrm{mg}, 0.1 \mathrm{mmol})$, and $\mathrm{H}_{2} \mathrm{O}$

(C) Xu X.-J., 2015 
Crystal data and structure refinement for complex $\mathbf{1}$

\begin{tabular}{l|c||l|c}
\hline \multicolumn{1}{c|}{ Parameter } & $\mathbf{1}$ & \multicolumn{1}{c}{ Parameter } & $\mathbf{1}$ \\
\hline Empirical formula & $\mathrm{C}_{14} \mathrm{H}_{11} \mathrm{~N}_{5} \mathrm{O}_{6} \mathrm{Zn}$ & $\rho_{\text {calcd }, \mathrm{g} / \mathrm{cm}^{3}}$ & 1.692 \\
Formula weight & 410.65 & $\mu\left(\mathrm{Mo} K_{\alpha}\right), \mathrm{mm}^{-1}$ & 1.568 \\
Crystal system & Monoclinic & Crystal size, $\mathrm{mm}$ & $0.21 \times 0.19 \times 0.17$ \\
Space group & $P 2_{1} / c$ & $\theta$ range, deg. & $2.13-26.00$ \\
$a, b, c, \AA$ & $9.6190(10), 8.783(9), 20.1010(18)$ & $F(000)$ & 832 \\
$\alpha, \beta, \gamma$, deg. & $90,108.290(4), 90$ & $R_{1}{ }^{a} / w R_{2}{ }^{b}[I>2 \sigma(I)]$ & $0.0587 / 0.1657$ \\
$V, \AA^{3}$ & $1612.4(17)$ & GOOF & 1.082 \\
$Z$ & 4 & &
\end{tabular}

T a b l e 2

Selected bond distances $(\AA)$ and angles (deg.) for complex $\mathbf{1}$

\begin{tabular}{c|c|c|c||c|c}
\hline $\mathrm{Zn}(1)-\mathrm{N}(2)$ & $2.015(5)$ & $\mathrm{O}(3)-\mathrm{Zn}(1)-\mathrm{N}(4)$ & $107.15(18)$ & $\mathrm{O}(5)-\mathrm{Zn}(1)-\mathrm{N}(2)$ & $111.74(17)$ \\
$\mathrm{Zn}(1)-\mathrm{O}(5)$ & $1.987(4)$ & $\mathrm{O}(5)-\mathrm{Zn}(1)-\mathrm{N}(4)$ & $111.48(18)$ & $\mathrm{N}(4)-\mathrm{Zn}(1)-\mathrm{N}(2)$ & $116.13(19)$ \\
$\mathrm{Zn}(1)-\mathrm{N}(4)$ & $2.002(4)$ & &
\end{tabular}

${ }^{\mathrm{i}} x+1, y, z$.

$(8 \mathrm{ml})$ was placed in a Teflon-lined stainless steel vessel, heated to $150{ }^{\circ} \mathrm{C}$ for 3 days, and then cooled to room temperature over $24 \mathrm{~h}$. Colorless crystals of 1 were obtained. Yield: $32.1 \%$ based on $\mathrm{Zn}$. Elemental analysis (\%) calcd. for $\mathrm{ZnC}_{14} \mathrm{~N}_{5} \mathrm{H}_{11} \mathrm{O}_{6}$ : C, 40.94; H, 2.70; N, 17.05. Found: C, 40.99; H, 2.71; N, 17.08. Selected IR (KBr, $\left.\mathrm{cm}^{-1}\right): 3257$ (m), 1623 (s), 1561 (s), 1457 (m), 1376 (s), 1273 (m), $981(\mathrm{~m}), 781(\mathrm{~m}), 729(\mathrm{~s})$.

X-ray crystallography. The crystal structure was determined on a Siemens (Bruker) SMART CCD diffractometer using monochromated $\operatorname{Mo} K_{\alpha}$ radiation $(\lambda=0.71073 \AA)$ at $296 \mathrm{~K}$. Absorption correction was applied using the SADABS program [ 13 ]. Intensities were collected by the $\omega$ scan technique and the structures were solved by direct methods and refined with full-matrix least-squares (SHELXTL-97) [14 ]. All non-hydrogen atoms were located in difference Fourier maps and refined anisotropically. Positions of hydrogen atoms in Im and aromatic dicarboxylate were determined by a theoretical calculation. The crystallographic data are summarized in Table 1. The selected bond lengths and angles are listed in Table 2.

Results and discussion. Single crystal X-ray diffraction reveals that complex 1 crystallizes in the monoclinic space group $P 2_{1} / c$ with an asymmetric unit consisting of a divalent zinc atom, a fully deprotonated $\mathrm{NO}_{2}-\mathrm{H}_{2} \mathrm{BDC}$ ligand, and two crystallographically distinct Im ligands. As shown in Fig. 1,

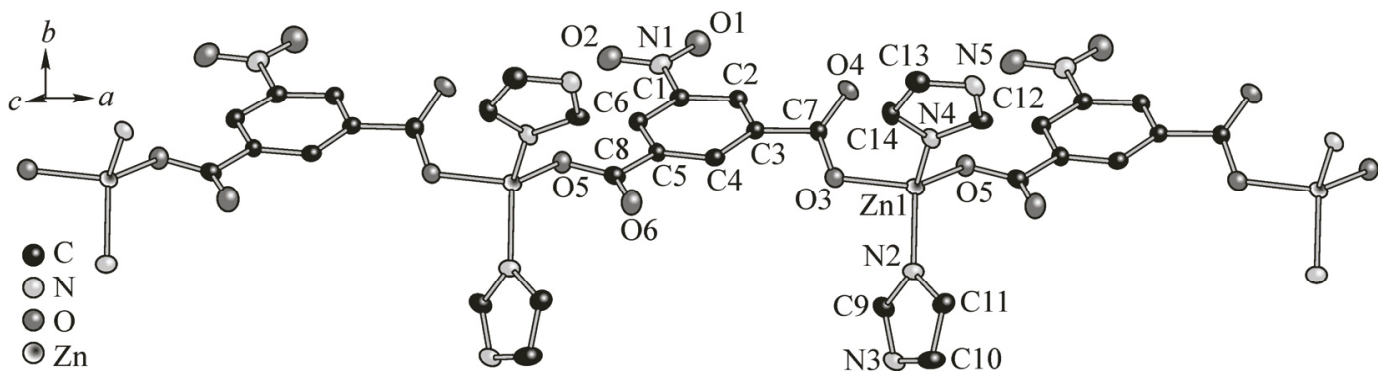

Fig. 1. 1D chain structure of complex 1; all hydrogen atoms are omitted for clarity 


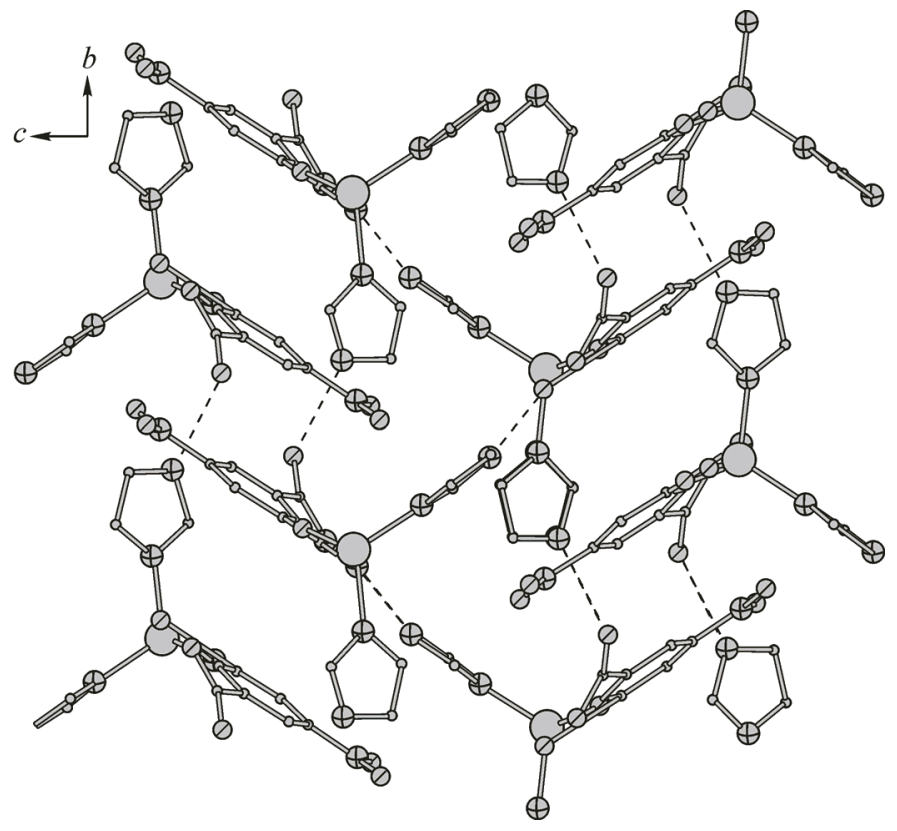

Fig. 2. H-bonds (dotted lines) between polymer chains. Projection of the crystal structure on the (100) plane; polymer chains are perpendicular to this plane

each $\mathrm{Zn}^{\mathrm{II}}$ center is coordinated by two $\mathrm{N}$ donor atoms from two different Im ligands [Zn1-N2= $=2.015(5), \mathrm{Zn} 1-\mathrm{N} 4=2.002(4) \AA]$ and two $\mathrm{O}$ donor atoms from monodentate carboxylate groups belonging to two different $\mathrm{NO}_{2}-\mathrm{BDC}^{2-}$ ligands $\left[\mathrm{Zn} 1-\mathrm{O} 3=1.965(5), \mathrm{Zn} 1-\mathrm{O} 5^{\mathrm{i}}=1.987(4) \AA\right.$, symmetry codes: $\left.{ }^{\mathrm{i}} x+1, y, z\right]$. The distortion of the tetrahedron can be indicated by the calculated value of the $\tau_{4}$ parameter; for a perfect square-planar geometry, $\tau_{4}=0$, and a perfect tetrahedral geometry is described when $\tau_{4}=1$ [ 15 ]. In complex $\mathbf{1}$, the calculated value of the $\tau_{4}$ parameter for the $\mathrm{Zn} 1$ atom is 0.93 , showing that the tetrahedral geometry is not perfect but distorted.

As to the $\mathrm{NO}_{2}-\mathrm{BDC}^{2-}$ anion, two carboxylate groups at $\mathrm{C} 7$ and $\mathrm{C} 8$ have the dihedral angles of $32.5(1)^{\circ}$ and $11.5(2)^{\circ}$ relative to the plane of their linking aromatic ring, respectively. The $\mathrm{NO}_{2}-\mathrm{BDC}^{2-}$ ligands in complex 1 adopt an exobidentate $\mu_{2}-\kappa^{2}-\mathrm{O}: \mathrm{O}^{\prime}$ binding mode, conjoining two $\mathrm{Zn} 1$ atoms. Each $\mathrm{Zn}$ atom is linked covalently to two others through two $\mathrm{NO}_{2}-\mathrm{BDC}^{2-}$ ligands, forming neutral 1D chains arranged parallel to the $\left(\begin{array}{lll}1 & 0 & 0\end{array}\right)$ crystal direction, while the Im ligands point in the same direction (Fig. 1). The $\mathrm{Zn} \cdots \mathrm{Zn}$ contact distance through the $\mathrm{NO}_{2}-\mathrm{BDC}^{2-}$ ligands is 9.6190(2) $\mathrm{A}$.

As seen in Fig. 2, adjacent 1D chains are linked with each other through $\mathrm{N}(3)-\mathrm{H}(3) \cdots \mathrm{O}(4)^{\mathrm{ii}}$, $\mathrm{N}(5)-\mathrm{H}(5) \cdots \mathrm{O}(6)^{\mathrm{iii}}$ and $\mathrm{C}(9)-\mathrm{H}(9) \cdots \mathrm{O}(5)^{\mathrm{iv}}\left({ }^{\mathrm{ii}}=x, y-1, z ;{ }^{\mathrm{iii}}=-x+2, y+1 / 2,-z+1 / 2{ }^{\mathrm{iv}}=-x+1,-y,-z\right)$ hydrogen bonding interactions to construct a $3 \mathrm{D}$ supramolecular architecture. In addition, this framework is reinforced by $\mathrm{C}-\mathrm{H}-\mathrm{C} \pi$ and $\mathrm{N}-\mathrm{O}-\mathrm{C} \pi$ interactions $\left[\mathrm{H} 10-C C \mathrm{~g} 1^{\mathrm{ii}}=2.54(3) \AA, \mathrm{C} 10-C C \mathrm{~g} 1^{\mathrm{ii}}=\right.$ $=3.402(8) \AA$ and $\mathrm{C} 10-\mathrm{H} 10-C C \mathrm{~g} 1^{\mathrm{ii}}=154(1)^{\circ} ; \mathrm{O} 2-C C \mathrm{gg} 1^{\mathrm{v}}=3.166(6) \AA, \mathrm{N} 1-C C \mathrm{~g} 1^{\mathrm{v}}=3.399(6) \AA$ and $\mathrm{N} 1-\mathrm{O} 2-C C \mathrm{~g} 1^{\mathrm{v}}=90.1(3)^{\circ}$; $\mathrm{O} 1-C C \mathrm{~g} 2^{\mathrm{vi}}=3.789(6) \AA, \mathrm{N} 1-C C \mathrm{~g} 2^{\mathrm{vi}}=3.390(6) \AA$ and $\mathrm{N} 1-\mathrm{O} 1-$ $C C \mathrm{~g} 2^{\mathrm{vi}}=62.0(3)^{\circ} ; \quad \mathrm{O} 2-C C \mathrm{gg} 2^{\mathrm{vi}}=3.663(6) \AA, \quad \mathrm{N} 1-C C \mathrm{~g} 2^{\mathrm{vi}}=3.390(6) \AA \quad$ and $\mathrm{N} 1-\mathrm{O} 2-C C \mathrm{~g} 2^{\mathrm{vi}}=$ $=67.6(3)^{\circ} ; C \mathrm{~g} 1$ and $C \mathrm{~g} 2$ are the centroids of the $\mathrm{N} 4-\mathrm{N} 5 / \mathrm{C} 12-\mathrm{C} 14$ and $\mathrm{C} 1-\mathrm{C} 6$ rings respectively; symmetry code: $\left.{ }^{\mathrm{v}} x-1,-y+1 / 2, z-1 / 2 ;{ }^{\mathrm{vi}}-x+1,-y+1,-z\right]$.

The phase purity of as-synthesized complex 1 was testified by X-ray powder diffraction (XRPD) experiment. The peak positions of the experimental and simulated XRPD patterns are in good agreement with each other, which demonstrates that complex $\mathbf{1}$ has been obtained successfully as a pure crystalline phase (Fig. 3). The differences in intensity may be due to the preferred orientation of the powder samples.

The solid state luminescent properties of complex 1 were investigated at room temperature. As shown in Fig. 4, complex 1 displays two emission peaks at $291 \mathrm{~nm}$ and $390 \mathrm{~nm}$, upon excitation at 


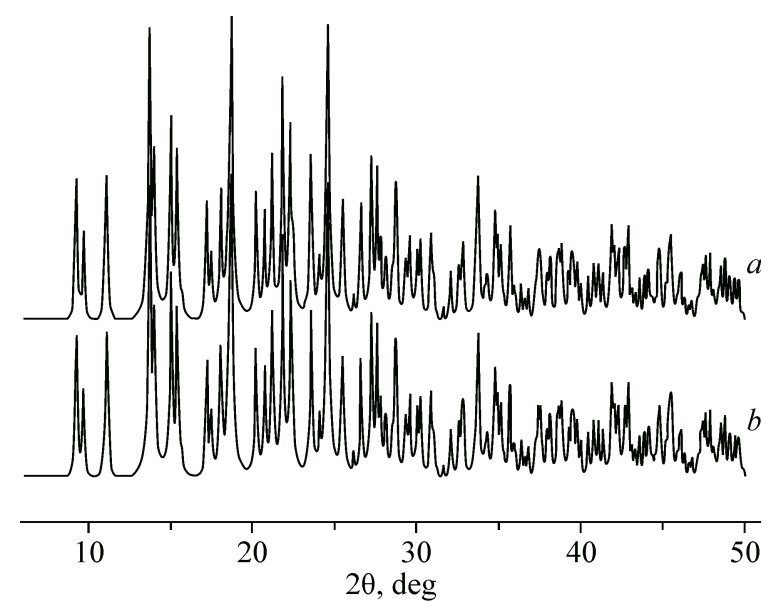

Fig. 3. Simulated ( $a$ ) and experimental (b) PXRD of complex 1

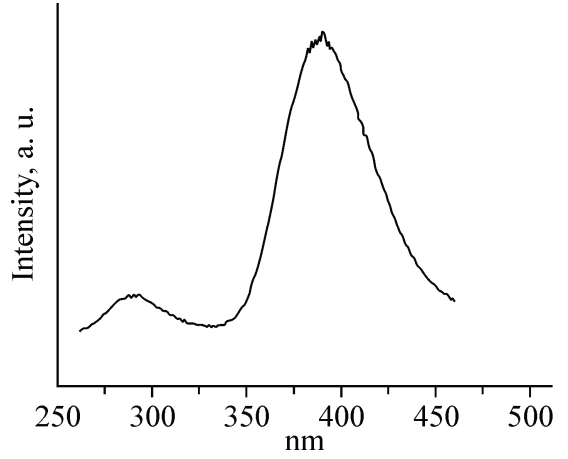

Fig. 4. The solid-state emission spectrum of complex 1 recorded at room temperature

$240 \mathrm{~nm}$. According to a recent review of $d^{10}$ metal coordination polymer luminescence [16], the emissive behavior of $\mathbf{1}$ can be ascribed to ligand-centered electronic transitions.

In summary, we have presented the synthesis and crystal structure of a new $1 \mathrm{D} \mathrm{Zn}$ (II) complex $\left[\mathrm{Zn}(\mathrm{Im})_{2}\left(\mathrm{NO}_{2}-\mathrm{BDC}\right)\right]_{n}(\mathbf{1})$. The single crystal X-ray diffraction analysis reveals that complex $\mathbf{1}$ is a one-dimensional chain polymer with a $\mathrm{Zn} \cdots \mathrm{Zn}$ separation of 9.6190(2) $\AA$. The chains are arranged parallel to the $\left(\begin{array}{lll}1 & 0 & 0\end{array}\right)$ crystal direction. Adjacent $1 \mathrm{D}$ chains are linked by $\mathrm{N}-\mathrm{H} \cdots \mathrm{O}, \mathrm{C}-\mathrm{H} \cdots \mathrm{O}$, $\mathrm{C}-\mathrm{H} \cdots \pi$ and $\mathrm{N}-\mathrm{O} \cdots \pi$ interactions to form a three-dimensional supramolecular architecture. In addition, the luminescence measurements reveal that complex 1 exhibits strong fluorescent emissions in the solid state at room temperature.

Crystallographic data for the structural analysis of complex $\mathbf{1}$ has been deposited at the Cambridge Crystallographic Data Centre, CCDC No. 1019869. Copy of the data can be obtained free of charge on application to CCDC, 12 Union Road, Cambridge CB2 1EQ, UK (fax: +44 1223336 033; e-mail: deposit@ccdc.cam.ac.uk).

\section{REFERENCES}

1. Wu C.D., Hu A.G., Zhang L. et al. // J. Am. Chem. Soc. - 2005. - 127. - P. 8940 - 8941.

2. Dinca M., Yu A.F., Long J.R. // J. Am. Chem. Soc. - 2006. - 128. - P. $8904-8913$.

3. Milon J., Daniel M.C., Kaiba A. et al. // J. Am. Chem. Soc. - 2007. - 129. - P. 13872 - 13878.

4. Lin J.G., Zang S.Q., Tian Z.F. et al. // CrystEngComm. - 2007. - 9. - P. 915 - 921.

5. Yang Y., Du P., Ma J.F. et al. // Cryst. Growth Des. - 2011. - 11. - P. $5540-5553$.

6. Chen Q., Jia Y.-Y., Chang Z. et al. // Cryst. Growth Des. - 2014. - 14. - P. $5189-5195$.

7. Demadis K.D., Armakola E., Papathanasiou K.E. et al. // Cryst. Growth Des. - 2014. - 14. - P. 5234 5243.

8. Zhao T., Zhang L., Wang D. et al. // CrystEngComm. - 2014. - 16. - P. 10181 - 10188.

9. Lu X., Ye J., Li W. et al. // CrystEngComm. - 2012. - 14. - P. 1337 - 1344.

10. Zhao F.-H., Che Y.-X., Zheng J.-M. // Inorg. Chem. Comm. - 2012. - 16. - P. 55 - 60.

11. Cheng D., Khan M.A., Houser R.P. // Inorg. Chem. - 2001. - 40. - P. 6858 - 6859.

12. Liu Y.-Y., Zhang T.-T., Ma J.-F. et al. // Inorg. Chem. Comm. - 2012. - 17. - P. 137 - 141.

13. Sheldrick G.M. SADABS, An empirical absorption correction program, Madison, WI, Bruker Analytical X-ray Systems, 1996.

14. Sheldrick G.M. SHELXL-97, Program for refinement of crystal structures, University of Göttingen, Germany, 1997.

15. Yang L., Powell D.R., Houser R.P. // Dalton Trans. - 2007. - P. 955 - 964.

16. Allendorf M.-D., Bauer C.-A., Bhakta R.-K. et al. // Chem. Soc. Rev. -2009. - 38. - P. $1330-1352$. 